\title{
I!:
}

\section{MOBILIDADE URBANA SUSTENTÁVEL: A IMPLANTAÇÃO DA LINHA VERDE EM VITÓRIA - ES}

\author{
URBAN SUSTAINABLE MOBILITY: THE IMPLANTATION OF LINHA \\ VERDE IN VITÓRIA - ES
}

\author{
${ }^{1}$ Lucas Caversan Gazolli. \\ ${ }^{2}$ Prof ${ }^{a}$. MSc. Lilia Márcia de Alvarenga Lourete. \\ ${ }^{1}$ Aluno no Curso de Especialização Lato Sensu em Administração Pública do IFES \\ ${ }^{2}$ Instituto Federal do Espírito Santo. E-mail: lilial@ifes.edu..
}

Artigo submetido em 15/11/2012, aceito em 12/12/2020 e publicado em 28/12/2020.

\begin{abstract}
Resumo: O presente trabalho tem o objetivo de analisar os impactos socioambientais decorrentes da Linha Verde, faixa exclusiva de ônibus, implantada no município de Vitória-ES em 2018. As faixas exclusivas de ônibus são uma forma de dar prioridade ao transporte coletivo nas vias e, por serem de simples de implantação e baixo custo, são utilizadas em várias cidades no mundo todo. Os resultados obtidos com elas são benéficos tanto para a mobilidade urbana quanto para o meio ambiente. Para atender ao objetivo principal, foram propostos os seguintes objetivos específicos: conhecer o projeto municipal de implantação da Linha Verde; verificar se a funcionalidade da mesma está de acordo com o planejado; comparar os resultados com os obtidos em outras cidades brasileiras que utilizaram o mesmo recurso. Por uma perspectiva metodológica qualitativa, o desenvolvimento deste trabalho se deu a partir de dados levantados na Secretaria de Transportes, Trânsito e Infraestrutura Urbana de Vitória (SETRAN) e de uma extensa revisão bibliográfica a respeito de mobilidade urbana sustentável e das faixas exclusivas. Como resultados, pode-se observar que a Linha Verde atende ao que foi proposto pois, ao priorizar o transporte coletivo, faz com que a velocidade dos ônibus aumente e, consequentemente, o tempo de viagem dos usuários diminui, melhorando a qualidade de vida dos mesmos. Já os impactos sobre meio ambiente, são de longo prazo, pois, para serem mais relevantes, é necessário que ocorra uma significativa migração de pessoas do transporte individual para o transporte coletivo, o que ainda não ocorreu em Vitória.
\end{abstract}

Palavras-chave: mobilidade urbana sustentável; transporte coletivo urbano; faixa exclusiva de ônibus; Linha Verde; Vitória-ES.

Abstract: The present work aims to analyze the socio-environmental impacts resulting from the Linha
Verde, an exclusive bus lane, implemented in Vitória - ES in 2018. The exclusive bus lanes priorize
public transport in the cities and, because they are easy to implement and their low cost, they are used
in several cities worldwide. The results obtained with them are beneficial for both urban mobility and
the environment. To achive the main objective, the following specific objectives were proposed: to
know the municipal project for implementing the Linha Verde; check if its functionality is in
accordance with the plan; compare the results with those obtained in other Brazilian cities that used
the same resource. In a qualitative methodological perspective, the development of this work was
based on data collected at the Secretariat of Transport, Traffic and Urban Infrastructure of Vitória
(SETRAN) and an extensive bibliographic review about sustainable urban mobility and exclusive
lanes. As a result, it can be seen that the Linha Verde reaches what was proposed because, by 
prioritizing public transport, it increases the speed of buses and, consequently, the travel time of users decreases, improving their quality of life. The impacts on the environment, on the other hand, are long-term, since, to be more relevant, it is necessary that there is a significant migration of people from individual transport to public transport, which has not yet occurred in Vitória

Keywords: urban sustainable mobility; urban public transportation; exclusive bus lane; Linha Verde; Vitória-ES.

\section{INTRODUÇÃO}

O Brasil experimentou um processo de urbanização muito acelerado, a partir de meados do século XX, especialmente a partir da década de 1970, porém, os investimentos em infraestrutura urbana não acompanharam o mesmo. De acordo com Trigueiro (apud ANDRADE et al, 2016, p. 8), o principal modelo de planejamento urbano no país, nos poucos locais em que houve, afastou o cidadão do local de trabalho, não investiu o suficiente em transporte público de massa e priorizou a utilização dos poucos recursos disponíveis em malhas rodoviárias para a circulação de carros (privilegiando a menor parcela da população) e ônibus (que, apesar de coletivo, não é considerado transporte de massa, como trem, metrô e barca). A isso, soma-se o incentivo ao uso do transporte individual nas décadas de 1990 e 2000, que contribuiu fortemente para o aumento da frota de veículos nas cidades.

Segundo Vasconcellos e Mendonça (2010), o setor automobilístico era (e ainda é) considerado importante pelo potencial de geração de empregos e por ser capaz de causar uma "onda" de crescimento econômico em diversos outros setores associados. Eles destacam, dentre as principais ações tomadas à época, a introdução do veículo popular em 1993, as reduções tributárias que a acompanharam e a contenção dos preços dos combustíveis.

Os brasileiros que residem nas grandes e médias cidades podem observar, quase todos os dias, as consequências dessa falta de planejamento urbano e das políticas citadas, como a grande quantidade de automóveis nas ruas, engarrafamentos quilométricos, aumento de acidentes automobilísticos, longas jornadas de ida e volta para o trabalho/casa, poluição do ar e sonora, entre outros. Dentre estes problemas, a poluição do ar é considerada um dos mais danosos para a saúde da população, pois contribui para o agravamento de doenças, em especial as respiratórias, e para o meio ambiente, principalmente por ser uma das principais causas do aquecimento global.

De acordo com o Observatório do Clima (2019), em 2018, o setor de energia (que inclui a produção e o consumo de combustíveis fósseis e também a geração de eletricidade) foi a terceira maior fonte de emissões de gases de efeito estufa (GEE) no Brasil - responsável por $21 \%$ do total nacional. E, dentro deste setor, os transportes são os que mais contribuem com as emissões, representando $49 \%$ destas - foram 200,2 milhões de toneladas de CO2e, só em 2018.

O transporte individual é o que mais contribui para esse número nas grandes e médias cidades. Cerca de $60 \%$ das emissões de dióxido de carbono nos centros urbanos brasileiros, são causadas por carros e motocicletas, enquanto o transporte público coletivo é responsável por cerca de $25 \%$ das emissões totais. Quando comparadas as emissões de poluentes por passageiro por quilômetro (Epkm), tem-se que os carros são 14,9 vezes mais poluidores que os ônibus (considerando a média de 1,5 passageiro por carro e 80 passageiros nos ônibus) (CARVALHO, 2011; FERREIRA, 2019).

Os problemas apontados não são exclusividade das cidades brasileiras. Por isso, segundo Trigueiro (apud ANDRADE et al, 2016, p. 8), várias cidades do mundo começaram a rever seus conceitos de mobilidade urbana. Observou-se que era necessário repensar o modelo e reordenar 
prioridades. Segundo o autor, em geral, o sucesso dos projetos foi proporcional à redução do espaço reservado aos automóveis nas cidades.

No Brasil, a Lei Federal número 12.587 de 2012, que institui as diretrizes da Política Nacional de Mobilidade Urbana, define, em seu parágrafo 4o, inciso II, mobilidade urbana como a "condição em que se realizam os deslocamentos de pessoas e cargas no espaço urbano" (BRASIL, 2012). Por afetar tanto a qualidade de vida dos cidadãos quanto o meio ambiente, é importante que a mobilidade urbana se torne cada vez mais sustentável. O caderno Mcidades 6 - Política nacional de mobilidade urbana sustentável, do Ministério das Cidades, define a mobilidade urbana sustentável como

\section{o resultado de um conjunto de políticas de transporte e circulação que visa proporcionar o acesso amplo e democrático ao espaço urbano, através da priorização dos modos não- motorizados e coletivos de transporte, de forma efetiva, que não gere segregações espaciais, socialmente inclusiva e ecologicamente sustentável. Ou seja: baseado nas pessoas e não nos veículos (BRASIL, 2004).}

A Agenda 2030, relatório elaborado pelo Instituto de Pesquisa Econômica Avançada (IPEA, 2018), apresenta propostas de adequação das metas globais para o Desenvolvimento Sustentável, da Organização das Nações Unidas (ONU), à realidade brasileira. $\mathrm{O}$ objetivo 11 do relatório é: tornar as cidades e os assentamentos humanos inclusivos, seguros, resilientes e sustentáveis. Dentre as metas, para que se alcance tal objetivo, é necessário, até 2030, proporcionar o acesso a sistemas de transporte seguros, acessíveis, sustentáveis e a preço justo para todos. Esse objetivo visa à melhoria da segurança rodoviária por meio da expansão dos transportes públicos coletivos, com especial atenção para as necessidades das pessoas em situação de vulnerabilidade, como mulheres, crianças, pessoas com deficiência e idosos.
O transporte coletivo é essencial nas cidades, pois democratiza a mobilidade (todos, independentemente da classe social, podem utilizar) e é fundamental para diminuir os congestionamentos, os níveis de poluição e o uso indiscriminado de energia automotiva, além de minimizar a necessidade de construção de vias e estacionamentos (ARAÚJO et al, 2011). Na visão de Araújo, e em concordância com ele, é oportuno complementar que os meios coletivos de transporte devem ser priorizados no planejamento urbano das cidades e é isso o que estabelece a Lei 12.587/2012 em seu parágrafo 6o, no qual são instituídas as diretrizes que orientam a Política Nacional de Mobilidade Urbana. Dentre essas diretrizes estão a "prioridade dos modos de transportes não motorizados sobre os motorizados, dos serviços de transporte público coletivo sobre o transporte individual motorizado" e "priorização de projetos de transporte público coletivo estruturadores do território e indutores do desenvolvimento urbano integrado" (BRASIL, 2012).

Diante do cenário exposto e compreendendo a relevância do transporte coletivo para o aumento da mobilidade e sustentabilidade dentro das cidades, o presente trabalho tem como objetivo analisar os impactos socioambientais decorrentes da implantação Linha Verde, uma faixa exclusiva para ônibus, em Vitória-ES.

\section{REFERENCIAL TEÓRICO}

Os principais meios de transporte coletivos em uso atualmente são o trem, metrô, VLT (veículo leve sobre trilho) e ônibus. Este último destaca-se por ser mais flexível (seus trajetos podem ser alterados conforme a conveniência) e por seu baixo custo de implantação e manutenção, quando comparado com os outros meios. De acordo com a Associação Nacional das Empresas de Transportes Urbanos (NTU, 2020), em cidades brasileiras com mais de 60 mil habitantes, $28 \%$ dos deslocamentos dentro das cidades são feitos por meio de transportes coletivos, e, desses, $85,7 \%$ são realizados por 
ônibus. Porém, esse número já foi maior. O Anuário 2018-2019 da NTU (2019) aponta que entre os anos de 1994 e 2012 a redução de demanda de passageiros pelos ônibus foi de 24,4\%, e entre 2013 e 2017 essa diminuição foi ainda maior, da ordem de $25,9 \%$. Dentre os principais motivos para essa queda estão os congestionamentos, a falta de priorização do transporte público na agenda do país e a redução de investimentos nessa área.

No Brasil, assim como em outros países em desenvolvimento e subdesenvolvidos, os recursos para investimentos são reduzidos e precisam suprir, além da mobilidade urbana, outras demandas igualmente urgentes como educação, saúde, habitação, segurança etc., deixando, por fim, todas apenas parcialmente atendidas (SILVA, 2019, p. 14). Isso, somado à falta de planejamento adequado, repercute numa infraestrutura (vias, pontos de ônibus, veículos, sinalização etc.) deficiente e não atrativa.

\subsection{IMPORTÂNCIA DAS FAIXAS EXCLUSIVAS DE ÔNIBUS}

As faixas exclusivas são uma solução encontrada pelas cidades para estabelecer certa prioridade para o transporte público e contribuem para a eliminação ou redução da interferência de veículos na operação dos serviços oferecidos pelo transporte público por ônibus (NTU, 2013). Segundo a Associação Nacional de Transportes Públicos (ANTP, 2017), a preferência à circulação dos ônibus nas cidades brasileiras começou em Curitiba, São Paulo e Belo Horizonte, nos anos de 1970. Depois de passar por grande aumento na década de 1980 , não houve ampliação relevante do número de faixas exclusivas nas décadas seguintes. Somente a partir dos anos 2010 a escolha por elas voltou a ser relevante, principalmente em razão da Copa da Fifa em 2014 e das Olimpíadas em 2016, eventos sediados no Brasil. Belo Horizonte, uma das cidades-sede da Copa, por exemplo, em 2014 já contava com, pelo menos, 16,2 quilômetros de faixas exclusivas para ônibus convencionais, de acordo com o Global BRTData (2020).

Uma faixa dedicada aos ônibus apresenta uma capacidade de transporte, em média, dez vezes superior a uma dedicada ao transporte privado (LINDAU et al, 2013). A cartilha "Política Nacional de Mobilidade Urbana", elaborada pelo Ministério das Cidades (BRASIL, 2013), destaca que a criação de espaços exclusivos para os ônibus nas vias garante a fluidez de maior quantidade de pessoas com menor impacto negativo ao meio ambiente. Ao melhorar a eficiência da operação do transporte coletivo, com o aumento da velocidade média, há economia de tempo, combustível e outros insumos, diminuindo, assim, os custos da operação, o que poderia viabilizar a redução de tarifa aos usuários e atrair mais pessoas para o transporte coletivo.

De acordo com o Instituto de Energia e Meio Ambiente (IEMA, 2017), as faixas exclusivas correspondem ao primeiro estágio de priorização do transporte coletivo. Não existem barreiras físicas separando as faixas, usa-se somente a sinalização horizontal e vertical para orientação dos condutores à correta utilização das mesmas. Isso desponta como uma das principais vantagens dessa estratégia de priorização do transporte coletivo já que para sua implantação é utilizada a estrutura viária já existente no local. O resultado disso é uma demanda de poucas intervenções a custo e tempo relativamente baixos, diferentemente da implantação de corredores exclusivos de ônibus (conhecidos como BRT - Bus Rapid Transit) que demandam maior planejamento e investimentos na construção de vias específicas e totalmente segregadas das demais faixas. Abaixo, no quadro 1, estão listados os principais objetivos e vantagens das faixas exclusivas de ônibus de acordo com a cartilha "Faixas Exclusivas de Ônibus Urbanos - Experiências de Sucesso" (NTU, 2013). 
Quadro 1: Objetivos e vantagens das faixas exclusivas de ônibus

\begin{tabular}{|c|c|}
\hline Objetivos das Faixas Exclusivas & Vantagens das Faixas Exclusivas \\
\hline $\begin{array}{l}\text { Garantir prioridade no sistema viário ao } \\
\text { transporte coletivo; }\end{array}$ & Implantação em curto prazo (entre 1 e 6 meses); \\
\hline $\begin{array}{c}\text { Aumentar a velocidade operacional dos } \\
\text { ônibus; }\end{array}$ & $\begin{array}{l}\text { Atendimento imediato às expectativas da população } \\
\text { usuária do transporte público por ônibus; }\end{array}$ \\
\hline $\begin{array}{c}\text { Diminuir o tempo do passageiro dentro do } \\
\text { veículo; }\end{array}$ & Não há necessidade de desapropriações; \\
\hline $\begin{array}{c}\text { Impactar positivamente nos deslocamentos } \\
\text { individuais; }\end{array}$ & $\begin{array}{l}\text { Baixo custo de implantação (de } 100 \text { mil a } 500 \text { mil } \\
\text { reais por quilômetro); }\end{array}$ \\
\hline $\begin{array}{l}\text { Permitir maior fluidez na circulação viária } \\
\text { para os ônibus; }\end{array}$ & $\begin{array}{l}\text { Fácil associação do projeto com a área urbana do } \\
\text { entorno; }\end{array}$ \\
\hline $\begin{array}{l}\text { Disponibilizar informação aos usuários, } \\
\text { monitoramento e reeducação; }\end{array}$ & Utilização dos ônibus já em operação na cidade; \\
\hline $\begin{array}{l}\text { Racionalizar a operação com a otimização da } \\
\text { frota; }\end{array}$ & $\begin{array}{l}\text { Redução do consumo de combustíveis (até 30\%) e } \\
\text { da emissão de poluentes (até } 40 \%)\end{array}$ \\
\hline $\begin{array}{l}\text { Aumentar a produtividade do transporte } \\
\text { público sobre pneus; }\end{array}$ & Redução de até $40 \%$ no tempo de viagem; \\
\hline $\begin{array}{c}\text { Reduzir os custos do transporte público e, } \\
\text { consequentemente, contribuir para a } \\
\text { modicidade tarifária; }\end{array}$ & Revitalização da área de intervenção; \\
\hline $\begin{array}{l}\text { Facilitar a integração com os outros modos de } \\
\text { transporte; }\end{array}$ & Impacto positivo na mobilidade da cidade. \\
\hline $\begin{array}{l}\text { Compartilhar os espaços da cidade de forma } \\
\text { justa e racional. }\end{array}$ & \\
\hline
\end{tabular}

Fonte: NTU - Faixas exclusivas de ônibus urbanos - Experiências de sucesso (2013).

No quadro apresentado, pode-se observar que os objetivos e as vantagens das faixas exclusivas elencados vão ao encontro do que estabelece a Lei Federal 12.587/2012 quanto à priorização do transporte público coletivo em detrimento do transporte individual, o que justifica e motiva o uso dessas faixas nas cidades, ainda mais por não demandarem custos elevados.

São inúmeros os estudos que apontam a efetividade das faixas exclusivas no melhoramento da qualidade dos deslocamentos via transporte coletivo nas cidades onde foram implantadas, principalmente quanto à diminuição do tempo da viagem dos usuários. Como exemplo, estudo realizado por Pontes et al (2014) aponta que, na Av. Pedro II, em Belo Horizonte, após a implantação da faixa exclusiva, houve um aumento médio de $7 \%$ na velocidade os ônibus. Os autores ainda destacam que o aumento não foi maior devido à ausência de uma faixa de ultrapassagem nos locais de paradas, fazendo com que os ônibus tenham que parar mesmo quando não é necessário. Já em Londrina, segundo Dutra e Becker (2015), nos trechos analisados por eles, que receberam faixas exclusivas, houve um ganho médio de 13 minutos nas viagens de ônibus, sendo que em um dos trechos o ganho médio foi de 20 minutos. Em São Paulo, cidade com maior número de faixas exclusivas, de acordo com Tatto (2015), a velocidade média dos ônibus nas faixas exclusivas passou de $14,3 \mathrm{~km} / \mathrm{h}$ para 20,1 km/h após 2013, quando foram implantados quase 600 subtrechos de faixas exclusivas na cidade.

Os benefícios que as faixas exclusivas trazem para o meio ambiente não são 
percebidos logo de imediato e para serem mais significativos é necessário que uma parcela da população deixe de utilizar automóveis para seus deslocamentos e optem pelo transporte coletivo, diminuindo, assim a quantidade de veículos nas vias e, consequentemente, a poluição do ar.

No entanto, pesquisas realizadas em cidades que adotaram as faixas exclusivas mostram que, somente por aumentar a velocidade dos ônibus, melhorando assim sua eficiência, já é possível observar diminuição da quantidade de gases poluentes emitida por eles. Destaca-se o trabalho realizado pelo Instituto de Energia e Meio Ambiente (IEMA, 2017) na cidade de São Paulo entre 2012 e 2014 que observou redução na taxa de consumo de diesel de $5,10 \%$ devido ao aumento da velocidade dos ônibus nas faixas exclusivas estudadas no período. Também foi observada diminuição das emissões de poluentes locais e gases de efeito estufa, as taxas de óxidos de nitrogênio, material particulado e gases responsáveis pelo efeito estufa caíram em 7,33\%, 6,07\% e 5,06\% respectivamente.

\subsection{IMPLANTAÇÃO DA LINHA VERDE NA CIDADE DE VITÓRIA-ES}

A cidade de Vitória é a capital do estado do Espírito Santo. De acordo com o Instituto Brasileiro de Geografia e Estatística (IBGE, 2020), sua população é estimada em 362 mil habitantes e sua extensão territorial é de aproximadamente $97,123 \mathrm{~km} 2$, o que a torna a cidade com a maior densidade demográfica do estado. A capital capixaba integra a Região Metropolitana da Grande Vitória (RMGV) com os municípios de Vila Velha, Serra, Cariacica, Viana, Fundão e Guarapari. Juntas, essas cidades abrigam, de acordo com o censo de 2010 do IBGE, quase metade da população do estado, ocupando apenas $4,2 \%$ do território do mesmo. Por ser o município de maior concentração de comércio e serviços e por sua localização central na RMGV, Vitória recebe, no horário comercial, um contingente populacional adicional similar a um terço dos seus habitantes. Por isso, nos horários de pico, observam-se engarrafamentos nas principais vias de acesso à cidade (SANTOS, 2018).

Assim sendo, é indispensável que a Prefeitura busque medidas que favoreçam o deslocamento intra e interurbano na cidade de Vitória, a fim de reduzir os problemas causados pelo grande número de carros nas vias públicas da cidade. Foi nesse sentido que, em 2018, optou-se pela implantação da Linha Verde na capital: uma faixa, inicialmente, exclusiva para meios de transporte coletivo.

O Relatório Técnico da Linha Verde, elaborado pela Secretaria de Transportes, Trânsito e Infraestrutura Urbana de Vitória (SETRAN, 2018), apresenta como principais objetivos da implantação de faixas exclusivas: dar agilidade aos corredores de ônibus, com a intenção de evitar paradas desnecessárias, e aumentar a segurança para o embarque e desembarque de passageiros dos coletivos. Ainda de acordo com o relatório, o transporte público coletivo deve ser priorizado, pois transporta cerca de $60 \%$ das pessoas nos horários de maior fluxo. $\mathrm{O}$ nome "Linha Verde" é uma referência à maior sustentabilidade dos transportes coletivos em relação aos individuais. Isso sugere que investir no transporte coletivo é investir também no meio ambiente e no desenvolvimento sustentável da cidade.

A Linha Verde está situada na Avenida Dante Michelini, com 5,05 quilômetros de extensão, sendo uma das principais vias de deslocamento ao longo da beira-mar e responsável pelo acesso a diversos bairros da capital. De acordo com o Plano Diretor Urbano de Vitória (VITÓRIA, 2018), essa é uma via arterial metropolitana que serve de ligação entre regiões da cidade, com corredores de conexão com cidades vizinhas e funciona na coleta e distribuição dos fluxos de veículos que circulam pelos centros metropolitanos com maior concentração de atividades. 
Figura 1: Recorte do mapa de Vitória-ES destacando a Avenida Dante Michelini.

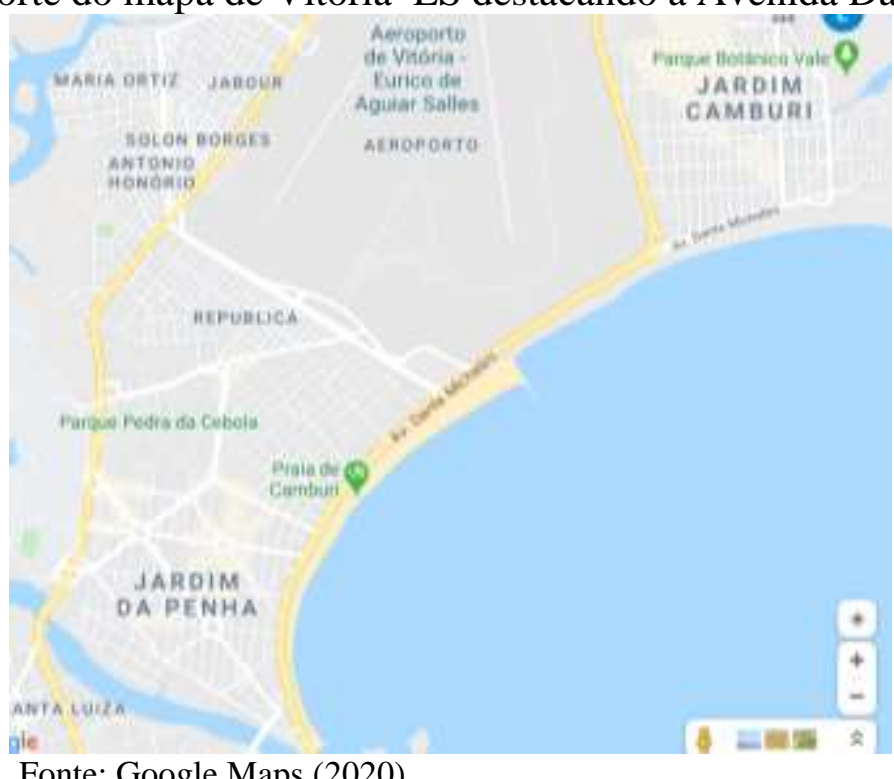

Fonte: Google Maps (2020).

Figura 2: Linha Verde, Vitória-ES.

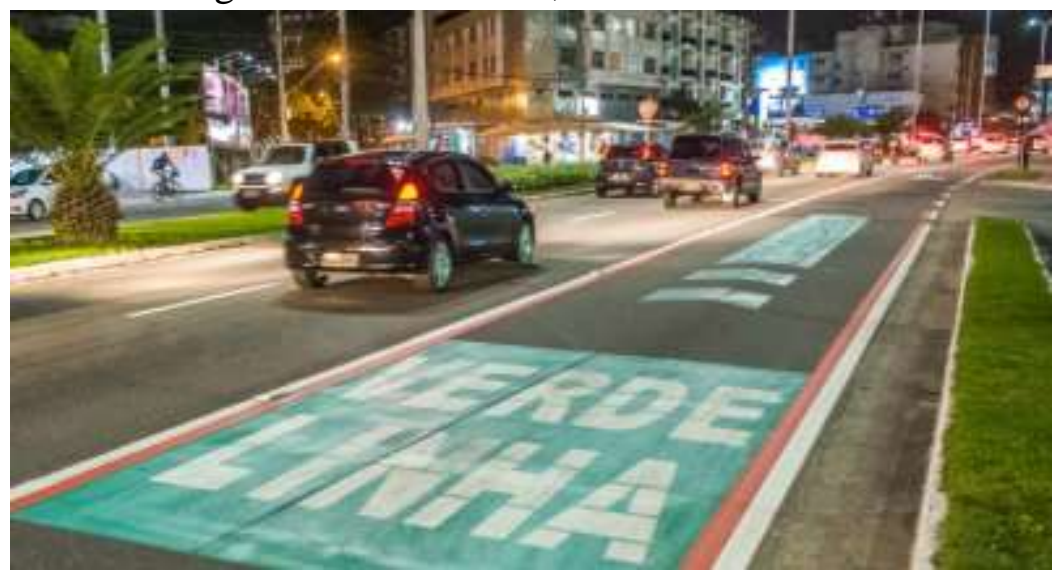

Fonte: Prefeitura Municipal de Vitória (2018).

A avenida tem duplo sentido de circulação com três faixas de rolamento por sentido e possui baias de ônibus com capacidade de atender simultaneamente até três ônibus. A faixa exclusiva funciona somente no sentido Jardim da Penha - Jardim Camburi, entre o píer de Iemanjá e o cruzamento da Avenida Dante Michelini com a Avenida Norte-Sul. Ela possui 3,8 quilômetros de extensão e está localizada na faixa da direita da pista em função dos pontos de ônibus ficarem nesse lado. O funcionamento da faixa exclusiva é de segunda a sexta-feira, das $6 \mathrm{~h}$ às $20 \mathrm{~h}$, e aos sábados, das $6 \mathrm{~h}$ às $14 \mathrm{~h}$.
Dentre os critérios utilizados para a escolha do eixo para implantação da Linha Verde, de acordo com o Estudo do Plano Diretor de Transporte e Mobilidade Urbana de Vitória - Faixa Exclusiva de Ônibus (EPDTMUV) da Prefeitura de Vitória (PMV, 2018), estão: a quantidade de linhas de transporte público que passam pelo trecho (tanto municipais quanto intermunicipais); a grande extensão da avenida com poucas conversões; as baias de ônibus, já existentes, que facilitam a ultrapassagem do transporte coletivo, sem que este interfira nas demais faixas do tráfico geral; a avenida possuir poucas conversões à direita, sendo estas somente para acesso a bolsões de 
Os principais elementos das faixas

estacionamento, o que facilita a fiscalização e reduz entraves para o transporte coletivo; não haver estacionamento na pista no trecho mais crítico da Linha Verde (entre o píer de Iemanjá e a altura do cruzamento da Avenida Dante Michelini com a Avenida Adalberto Simão Nader); o volume de ônibus no trecho ser superior a 40 ônibus por hora; e a faixa exclusiva não alterar o perfil de tráfego de veículos na avenida, com os ônibus permanecendo na pista da direita.

\subsection{ELEMENTOS DAS FAIXAS EXCLUSIVAS DE ÔNIBUS}

Figura 3: Principais elementos das faixas exclusivas.

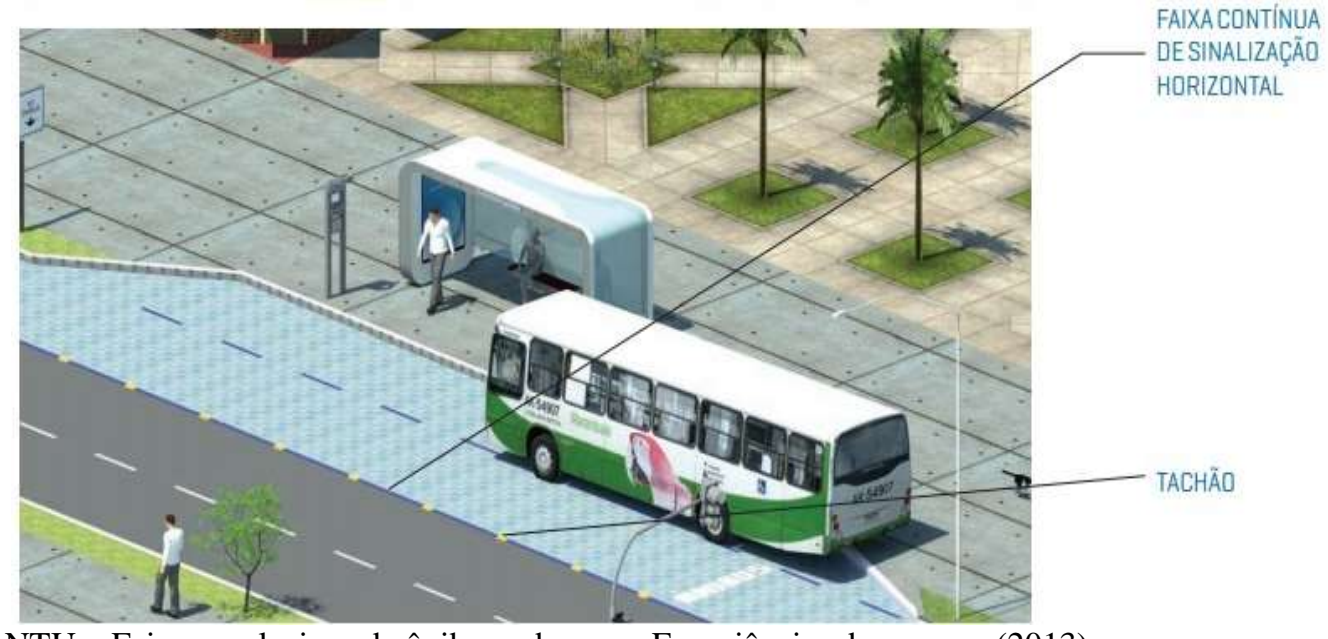

Fonte: NTU - Faixas exclusivas de ônibus urbanos - Experiências de sucesso (2013) exclusivas, de acordo com a NTU (2013) são:

1) Faixa contínua de sinalização horizontal, que delimita o espaço viário dedicado à circulação do ônibus e indica a prioridade do transporte público;

2) Ondulação transversal (tachão), elemento físico de dimensões reduzidas que serve como separador do espaço para o ônibus do tráfego misto e também como inibidor da invasão do espaço do transporte público;

\begin{abstract}
3) Faixa não contínua de sinalização
horizontal, a qual sinaliza no espaço viária
área que os veículos particulares podem
utilizar para realizar conversões à direita;
3) Faixa não contínua de sinalização
horizontal, a qual sinaliza no espaço viária
área que os veículos particulares podem
utilizar para realizar conversões à direita;

3) Faixa não contínua de sinalização
horizontal, a qual sinaliza no espaço viária
área que os veículos particulares podem
utilizar para realizar conversões à direita;

3) Faixa não contínua de sinalização
horizontal, a qual sinaliza no espaço viária
área que os veículos particulares podem
utilizar para realizar conversões à direita;
\end{abstract}

Figura 4: Principais elementos das faixas exclusivas.
4) Radares eletrônicos (pardais), para fiscalização eletrônica e autuação através da detecção da presença e utilização do espaço da faixa exclusiva por outros veículos que não sejam os ônibus; 


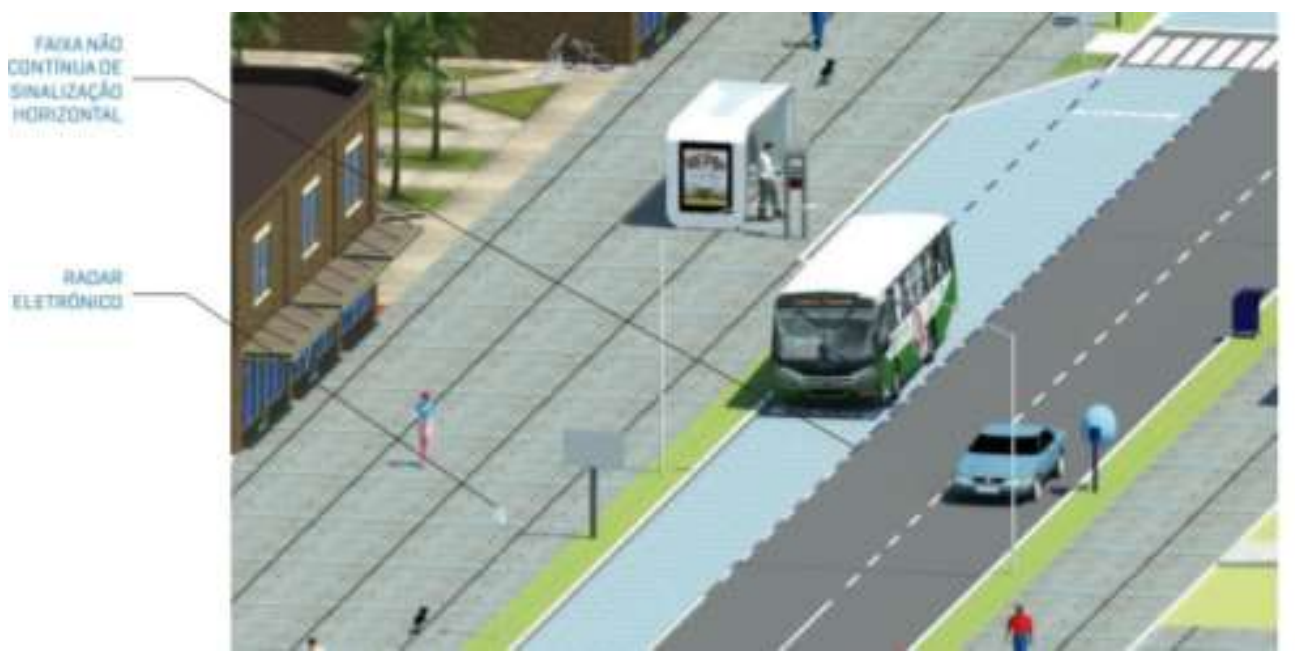

Fonte: NTU - Faixas exclusivas de ônibus urbanos - Experiências de sucesso (2013).

5) Placas de sinalização vertical, que indicam a proibição do uso da faixa do transporte público para outros veículos não autorizados;

6) Recuos (baias) das paradas de ônibus (pequenas modificações da via e do mobiliário urbano para que as operações de embarque e desembarque de passageiros dos ônibus possam ocorrer sem interferir no fluxo de veículos que utilizam a faixa exclusiva).

Figura 5: Principais elementos das faixas exclusivas.

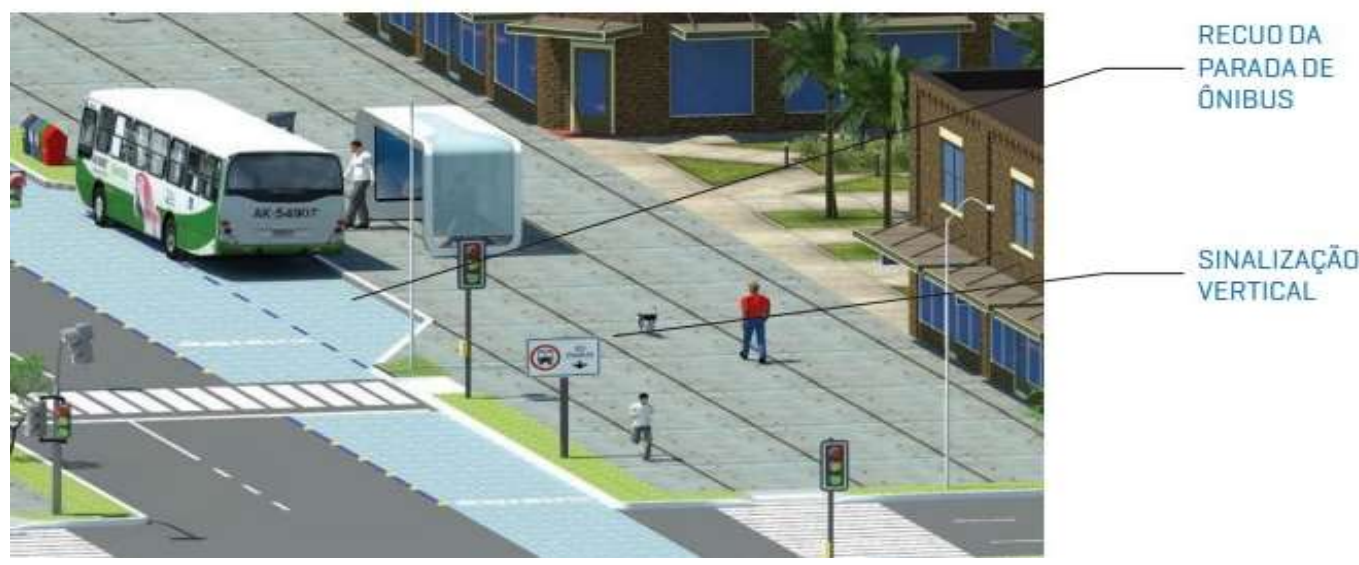

Fonte: NTU - Faixas exclusivas de ônibus urbanos - Experiências de sucesso (2013).

Em Vitória, para identificação da Linha Verde, foram colocadas placas de sinalização vertical e a pista recebeu também sinalização horizontal, com pintura no pavimento de legendas como "linha verde" e "só ônibus", além da instalação de tachões a cada 1 metro. Também foram instaladas 16 câmeras de videomonitoramento em pontos do trajeto para auxiliar a fiscalização. As baias de ônibus nos pontos de parada já existentes no trecho contribuíram para que se realizassem menos intervenções e, consequentemente, a um custo menor.

\section{DA LINHA VERDE EM VITÓRIA-ES}

O funcionamento da Linha Verde iniciou-se em 12 de março de 2018 e os primeiros dias foram um tanto conturbados, sendo registrados grandes congestionamentos durante o horário de pico. Sobre isso, reportagem do jornal A Gazeta de 20 de 
março de 2018 destaca que o secretário de Transportes, Trânsito e Infraestrutura Urbana de Vitória (SETRAN) à época, Tyago Hoffmann, disse que "quando se implanta algo novo, tem problemas que você só vê quando a operação começa" e afirmou que seriam feitas revisões nos tempos dos semáforos para adequá-los ao novo tráfego na avenida. A implantação da faixa exclusiva dividiu opinião dos que trafegavam por ela, motoristas reclamaram do trânsito mais lento para eles e usuários dos transportes coletivos alegaram que as viagens ficaram mais rápidas.

Como consequência dessas manifestações, acatando o pedido de uma moradora do bairro Jardim Camburi, na capital, a justiça suspendeu, em 21 de março de 2018, o funcionamento da faixa exclusiva. $\mathrm{Na}$ decisão, o juiz considerou as afirmações feitas pela popular de que a implantação da Linha Verde

consumiu recursos públicos, violou as disposições da Lei Federal $\mathrm{n}^{\circ}$ $12.587 / 2012$, que trata da política nacional de mobilidade, trazendo como princípio da mobilidade urbana a gestão democrática e controle social do planejamento. Da mesma forma, trouxe desequilíbrio ambiental, violação do princípio do meio ambiente ecologicamente equilibrado, violação do direito à cidade e mobilidade urbana (ESPÍRITO SANTO, 2018a).

Ainda, em sua decisão, o juiz chamou a atenção para a "enorme dificuldade" de locomoção encontrada pela população que utiliza seu próprio veículo para "exercer o seu sagrado direito de ir e vir", se deparando com "intermináveis congestionamentos decorrentes da implantação da Linha Verde".

Em relação a esse ponto, Paradeda et al. (2015) afirmam que, devido à implantação de faixas exclusivas para transporte coletivo, a diminuição do espaço para circulação de automóveis pode causar piora nas condições de tráfego de automóveis nos horários de pico. Os autores ainda afirmam que há uma parcela da população usuária do automóvel que entende essa diminuição do espaço como diminuição da mobilidade na cidade. Tal questão gera pressão política e dificuldade por parte de gestores públicos de tomarem decisões em favor do transporte coletivo. Cabe a esses gestores apresentarem dados qualitativos e quantitativos quanto aos benefícios das faixas exclusivas, para justificar as decisões de política pública em favor dos ônibus.

Além disso, há estudos que afirmam que apesar da sensação de maior congestionamento, a velocidade média dos carros, em alguns casos, também aumenta, mesmo confinados em menos vias. É oportuno destacar o estudo realizado por Oliveira et al (2018), o qual mostrou que em São Paulo a velocidade média dos veículos que trafegavam fora das faixas exclusivas variou entre $0 \%$ e $+4,55 \%$, levando à conclusão de que a velocidade média desses veículos aumenta ou, no mínimo, não é afetada. Ainda sobre essa questão, Mota et al (2019) constatou que não há alteração significativa para o tráfego nas demais faixas e conclui que isso é possível pois, ao segregar os ônibus dos demais veículos, há uma reorganização do tráfego, uniformizando-o, o que garante fluidez ao trânsito.

Em decisão favorável à Linha Verde, no dia 28 de março de 2018, a liminar que proibia o seu funcionamento foi cassada pela Justiça Estadual. $\mathrm{O}$ desembargador responsável pela decisão alegou que o município realizou as audiências públicas antes da implementação do Projeto Linha Verde e, com relação aos congestionamentos decorrentes da implantação da faixa exclusiva, ressaltou que

o Município nada mais fez do que cumprir o determinado na legislação local (Lei n. 6.705/2006) e federal (Lei n. 12.587/2012) priorizando o transporte PÚBLICO em detrimento do transporte PARTICULAR, não havendo, segundo consta, qualquer ilegalidade em tal procedimento. [...] cabe ao administrador [...] avaliar o sucesso ou não do projeto, o qual, 
consigno, está dentro de uma tendência adotada por várias grandes cidades do nosso país, sendo vedado ao Judiciário, conforme acima exposto, a implementação de análises desse tipo, quando ausente a violação a legalidade estrita, como aparentemente ocorreu na situação posta (ESPÍRITO SANTO, 2018b).

Com isso, a Linha Verde voltou a funcionar no dia 10 de abril de 2018, sendo permitido também a utilização de carros de passeio com três ou mais passageiros, a chamada carona solidária. Conforme reportagem do jornal A Gazeta do dia 02 de abril de 2018, o secretário Tyago Hoffmann disse que o que se buscava era incentivar o transporte coletivo ou solidário pois "a cidade não suporta mais os veículos com um só passageiro, uma só pessoa". Então, a partir desse dia, foram permitidos trafegar na Linha Verde: ônibus do transporte público, ônibus escolares, particulares e de excursão e turismo, além de micro-ônibus, táxis, vans e veículos com três ou mais passageiros.

Entretanto, a permissão da carona solidária trouxe uma dificuldade para a fiscalização do uso da Linha Verde, pois as câmeras instaladas não conseguiriam detectar o número de passageiros nos veículos transitando por ela. Por causa disso, por mais de um ano após a retomada do funcionamento da faixa exclusiva, não houve controle sobre os carros que transitavam por ela e nem penalização para os infratores. Somente no fim de novembro de 2019 é que a Prefeitura de Vitória passou a multar os motoristas que descumpriam a regra.

Guardas de trânsito são agora os responsáveis por fiscalizar a utilização da Linha Verde. O valor da multa é de $\mathrm{R} \$ 130,16$ além da perda de 4 pontos na carteira de habilitação e tem base no artigo 187 do Código de Trânsito Brasileiro que prevê multa por transitar em locais e horários não permitidos pela regulamentação estabelecida pela autoridade competente (BRASIL, 1997). De acordo com o secretário de Segurança Urbana de Vitória, Fronzio Calheira, em entrevista para o jornal Tribuna
Online em 24 de novembro de 2019, a maioria dos motoristas já respeitava a Linha Verde, mesmo sem a aplicação de multa. Segundo ele, levantamento feito nos últimos meses apontava que mais de $60 \%$ dos condutores já obedeciam às regras.

\section{PERCURSO METODOLÓGICO}

Políticas públicas orientadas para mobilidade urbana sustentável na cidade de Vitória-ES: implantação da Linha Verde é o tema central deste trabalho. A inquietude que levou à pesquisa surgiu do seguinte questionamento: quais análises socioambientais podem ser feitas resultantes da implantação da Linha Verde em VitóriaES? Com o propósito de responder tal questionamento científico, foi traçado como objetivo geral, analisar os impactos socioambientais decorrentes da Linha Verde no município de Vitória-ES.

A fim de atender ao objetivo principal e responder à pergunta levantada, foram percorridos os seguintes objetivos específicos: conhecer o projeto municipal de implantação da Linha Verde no município de Vitória-ES; verificar se a funcionalidade da Linha Verde está de acordo com o planejado; comparar os resultados com os obtidos em outras cidades brasileiras que utilizaram o mesmo recurso como estratégia para melhorar a mobilidade urbana e torná-la mais sustentável.

Este trabalho trata-se de uma pesquisa qualitativa do tipo documental. De acordo com Neves (1996), faz parte deste tipo de pesquisa a "obtenção de dados descritivos mediante contato direto e interativo do pesquisador com a situação objeto de estudo" e para seu desenvolvimento, supõe-se um corte temporal-espacial de determinado fenômeno pelo pesquisador, o que definirá o campo e a dimensão em que o trabalho será elaborado. Segundo Godoy (1995), a pesquisa qualitativa documental faz o exame de materiais que ainda não receberam um tratamento analítico ou que podem ser reexaminados com intenção de uma 
interpretação nova ou complementar. Dentre as vantagens deste método, Kripka et al (2015, apud Guba e Lincoln, 1981) destacam que os documentos constituem fonte estável e rica de onde o pesquisador poderá retirar evidências que fundamentam suas afirmações, além disso, eles podem ser consultados várias vezes e podem ratificar, validar ou complementar informações obtidas por outras técnicas de coleta de dados.

Após a definição dos objetivos, realizou-se uma ampla revisão bibliográfica a respeito do tema mobilidade urbana sustentável, mais especificamente sobre as faixas exclusivas de ônibus, fundamentada em livros, artigos científicos, dissertações e sites institucionais. E em seguida foram levantados dados específicos referentes à implantação da Linha Verde na Secretaria de Trânsito, Transporte e Infraestrutura Urbana (SETRAN) do município, no sítio eletrônico do judiciário estadual e nos meios de comunicação locais.

\section{RESULTADOS E DISCUSSÃO}

Apesar dos impasses na implantação e funcionamento, os efeitos da Linha Verde puderam ser notados pelos usuários dos transportes coletivos. Em parecer técnico com data de 22 de março de 2018, enviado à
Câmara de Vereadores de Vitória, a Prefeitura Municipal de Vitória (PMV, 2018) informa que, por meio do sistema de controle de viagens e itinerários do transporte coletivo, que monitora o sistema de transporte municipal por meio de GPS instalado nos ônibus, foi possível observar melhora considerável no tempo das viagens dos coletivos, a exemplo da linha de ônibus municipal 211 que faz o trajeto entre os bairros Santo André e Jardim Camburi na capital.

No dia 27/02/2018, terça-feira, antes da implantação da faixa exclusiva, de acordo com o parecer, a viagem programada para o horário das 18h15min (horário de pico do trânsito e de demanda de passageiros) durou 2h51min. Já no dia 20/03/2018 também terça-feira, porém, posterior à implantação da Linha Verde, a viagem, no mesmo horário, durou $2 \mathrm{~h} 41 \mathrm{~min}$, dez minutos mais rápida.

Também pôde ser constatado que, após a implantação faixa exclusiva, os veículos que trafegam nas outras faixas não foram impactados negativamente, ao contrário do que muitos motoristas alegaram no início do funcionamento. Segundo consta no Relatório da Implantação da Linha Verde elaborado e disponibilizado pela SETRAN, houve, inclusive, redução de $16 \%$ no tempo médio das viagens dos carros particulares, como mostra a tabela abaixo

Tabela 1: Monitoramento de tempo de viagens de veículo individual sem a Linha Verde Pesquisa tempo de percurso (Praça do Papa x Saída Norte Sul) - 27/03/2018

\begin{tabular}{|c|c|c|c|c|c|}
\hline Horário & Ônibus & Carro & Praça do Papa & Norte-Sul & Tempo Total \\
\hline $17: 40$ & & $\mathrm{X}$ & $17: 40$ & $18: 11$ & $00: 31$ \\
\hline $18: 00$ & & $\mathrm{x}$ & $18: 00$ & $18: 32$ & $00: 32$ \\
\hline $18: 20$ & & $\mathrm{x}$ & $18: 20$ & $18: 56$ & $00: 36$ \\
\hline $18: 40$ & & $\mathrm{x}$ & $18: 40$ & $19: 21$ & $00: 41$ \\
\hline $19: 00$ & & $\mathrm{X}$ & $19: 00$ & $19: 31$ & $00: 31$ \\
\hline \multirow[t]{2}{*}{$19: 20$} & & $\mathrm{X}$ & $19: 20$ & $19: 39$ & 00:19 \\
\hline & & & & Tempo Médio & $00: 31$ \\
\hline
\end{tabular}

Fonte: Resumo do Relatório da Primeira Fase da Implantação da Linha Verde na Dante Michelini, PMV (2018).

Tabela 2: Monitoramento de tempo de viagens de veículo individual com a Linha Verde Pesquisa tempo de percurso (Praça do Papa x Saída Norte Sul) - 25/04/2018

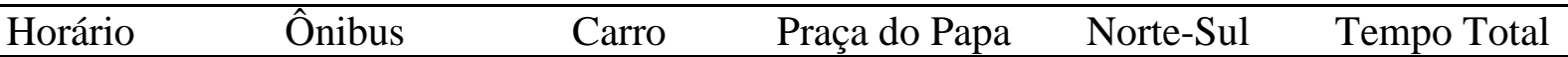




\begin{tabular}{ccccc}
$17: 40$ & X & $17: 40$ & $18: 06$ & $00: 26$ \\
$18: 00$ & X & $18: 05$ & $18: 32$ & $00: 27$ \\
$18: 20$ & X & $18: 24$ & $18: 57$ & $00: 33$ \\
$19: 00$ & X & $19: 05$ & $19: 32$ & $00: 27$ \\
$19: 20$ & X & $19: 23$ & $19: 43$ & $00: 20$ \\
$19: 40$ & X & $19: 44$ & $20: 10$ & $00: 26$ \\
\hline \multicolumn{5}{l}{} \\
Fonte: Resumo do Relatório da Primeira Fase da Implantação da Linha Verde na Dante Michelini, PMV (2018).
\end{tabular}

Esse relatório, alinhado aos estudos citados, justifica esse aumento pelo maior controle do volume e velocidade média dos veículos em cada trecho e afirma que, apesar de ter aumentado a sensação de congestionamento por causa do confinamento dos carros em somente duas pistas, o tempo total do percurso foi menor.

O mesmo relatório ainda apontou que o tempo médio das viagens de ônibus no mesmo percurso (Praça do Papa x saída da Avenida Norte-Sul) no período de 06 a 09 de março de 2018, antes do início do funcionamento da Linha Verde, foi de $41 \mathrm{~min}$. Em contrapartida, nos dias 25 e 26 de abril de 2018 o tempo médio dos coletivos no percurso com a Linha Verde funcionando caiu para $26 \mathrm{~min}$, uma redução de 15 minutos (36\%) no tempo das viagens.

Os resultados obtidos pela SETRAN, mostram que a implantação da Linha Verde cumpre o seu principal objetivo que é aumentar a velocidade dos ônibus na faixa exclusiva e com isso diminuir a duração das viagens de ônibus dos usuários que passam por aquele trecho. Reportagem feita pelo jornal CBN Vitória, publicada em 21 de março de 2019, destaca que a maioria dos passageiros dos transportes coletivos aprovam o projeto, o que demonstra sua eficácia. A opção de permitir que carros com três ou mais passageiros utilizem a Linha Verde, apesar de modificar a finalidade original, não alterou significativamente o fluxo dos ônibus na faixa e contribuiu para que o tráfego nas outras faixas tivesse maior vazão, diminuindo os engarrafamentos, o que foi visto como um ponto positivo pelos motoristas de automóveis e pode ser confirmado na mesma reportagem citada acima.

A Prefeitura de Vitória tem intenção de ampliar a Linha Verde. Inclusive, logo após a implantação da mesma, em 2018, foram realizados testes para expansão da faixa até o Horto Mercado, no bairro Enseada do Suá, o que totalizaria cerca de 9 quilômetros de faixa. No entanto, temporariamente a Prefeitura abandonou esse projeto. Em relação a essa ampliação, apesar de aumentar a eficácia da faixa exclusiva, reduzindo ainda mais o tempo das viagens de ônibus, existe maior resistência da população devido ao trecho ser um dos que registram os maiores congestionamentos nos horários de pico na cidade.

Em relação aos impactos ambientais, ainda não há estudos que indiquem melhora ou piora dos níveis de poluição na cidade de Vitória decorrentes da implantação da Linha Verde. No entanto, pelo pouco tempo de funcionamento e por não ter conseguido atrair muitas pessoas para o transporte coletivo, depreende-se que os benefícios para o meio ambiente não foram significativos.

$\mathrm{Na}$ página da internet da Agência Nacional de Transportes Públicos (ANTP, 2020), um simulador de impactos ambientais em ações de mobilidade urbana, desenvolvido em parceria com a Organização Não Governamental WWF-Brasil, que atua nas áreas da conservação, investigação e recuperação ambiental, ilustra os resultados que a mudança nos meios de locomoção pode trazer para uma cidade. A simulação para a cidade de Vitória-ES estima que se houvesse uma troca de $20 \%$ dos deslocamentos feitos de auto para ônibus, diminuiria em $19 \%$ as 
emissões de poluentes locais e em $6 \%$ as emissões de dióxido de carbono (CO2), principal gás causador do efeito estufa. A Agência, no entanto, lembra que os valores são estimados por processos estatísticos, para sensibilização a respeito da ordem de grandeza dos impactos.

\section{CONSIDERAÇÕES FINAIS}

O que se almeja com a implantação das faixas exclusivas que priorizam o transporte coletivo é motivar a população a optar por esse meio em seus deslocamentos. Tal medida diminui a grande quantidade de veículos nas vias e os problemas causados por ela, como os engarrafamentos e a grande emissão de gases poluentes. No entanto, para que as pessoas que possuem carro passem a utilizar ônibus é preciso oferecer-lhes muito mais do que somente um tempo menor de viagem. Os governos em conjunto com as empresas prestadoras de transporte público devem adotar medidas que garantam a qualidade do transporte coletivo (boa distribuição, conforto, segurança no trânsito, possibilidade de integração no espaço da cidade, aumento da velocidade e regularidade das linhas), buscar a manutenção de preço acessível das passagens e conciliar isso com restrições ao uso inadequado do automóvel.

O que pode ser observado na cidade de Vitória é que o "primeiro passo", dado pela Prefeitura com a implantação da Linha Verde, trouxe como ponto positivo a redução no tempo das viagens de ônibus. Isso agradou principalmente àqueles que já faziam uso dos mesmos, o que é muito importante, pois afeta positivamente a qualidade de vida dessas pessoas, mas não foi suficiente para fazer com que a maioria das pessoas que utilizam carros particulares passassem a utilizar o transporte coletivo. Por isso, apesar de não haverem estudos que comparem os níveis de poluição no município antes e depois da Linha Verde pode-se pressupor que os impactos ambientais decorrentes da implantação da faixa exclusiva não são tão relevantes.
As pesquisas feitas para o desenvolvimento deste trabalho apontam para a necessidade de mais investimentos em transporte coletivo de forma a garantir aos usuários acesso a serviços com maior qualidade. A ampliação da Linha Verde e a implantação de faixas exclusivas em outras avenidas na cidade de Vitória, como a Av. Fernando Ferrari e a Av. Nossa Senhora da Penha, também são pontos que deveriam ser analisados pela prefeitura. Essas medidas visam atrair maior número de pessoas para o transporte coletivo. Ainda no decorrer desta pesquisa, poucos foram os dados encontrados sobre os impactos ambientais decorrentes da implantação e funcionamento da Linha Verde, fato que merece atenção, pois se trata de um tema de grande importância no que se refere à qualidade de vida na cidade e a questões ambientais e econômicas.

\section{REFERÊNCIAS}

ANTP (Associação nacional de transportes públicos). Mobilidade urbana para um Brasil urbano. 2017. Disponível em: <http://files.antp.org.br/2017/7/12/antpmobilidade-humana-11-07-2017--baixa.pdf> Acesso em:14 mar 2020.

\section{Simulador de Impactos}

Ambientais. ANTP, 2020. Disponível em: <http://www.antp.org.br/simulador/impactosambientais/> Acesso em 28 abr 2020.

ARAÚJO, Marley Rosana Melo de et al. Transporte público coletivo: discutindo acessibilidade, mobilidade e qualidade de vida. Psicologia \& Sociedade, v. 23, n. 3, p. 574-582, 2011.

BOURGUIGNON, Natalia. Apesar das críticas, prefeitura não vai abrir mão da Linha Verde. A Gazeta. Vitória, 20 de mar de 2018. Disponível em: $<$ https://www.agazeta.com.br/es/gv/apesardas-criticas-prefeitura-nao-vai-abrir-mao-dalinha-verde-0318> Acesso em 14 mar 2020. 
BRASIL. Lei ${ }^{\circ} 12.587$, de 03 de janeiro de 2012. Institui as diretrizes da Política

Nacional de Mobilidade Urbana e dá outras providências. Diário Oficial da República

Federativa do Brasil. Brasília, 04 jan 2012. Disponível em:

<http://www.planalto.gov.br/ccivil_03/_ato2 $011-2014 / 2012 /$ lei/112587.htm> Acesso em 22 abril 2020

\section{MINISTÉRIO DAS CIDADES.}

Política nacional de mobilidade urbana sustentável. Ministério das Cidades, 2004. Disponível em: <http://www.ta.org.br/site2/ Banco/7manuais/ 6PoliticaNacional MobilidadeUrbanaSustentavel.pdf $>$ Acesso em 06 jul 2020.

\section{MINISTÉRIO DAS CIDADES.}

Política Nacional de Mobilidade Urbana: Cartilha da Lei número 12.587/12. Brasília: Ministério das Cidades, 2013. Disponível em: <http://www.portalfederativo.gov.br/ noticias/destaques/municipios-devemimplantar-planos-locais-de-mobilidadeurbana/ CartilhaLei12587site.pdf> Acesso em 03 mar 2020.

Lei $n^{\circ} 9.503$, de 23 de setembro de 1997. Institui o Código de Trânsito Brasileiro. Diário Oficial da República Federativa do Brasil. Brasília, 23 jan 1997. Disponível em: <http://www.planalto.gov.br /ccivil_03/leis/19503.htm> Acesso em 16 mar 2020.

BRT+ Centre of Excellence e EMBARQ. “Global BRTData.” Versão 3.48. Última modificação: 13 jan 2020. Disponível em: $<$ https://brtdata.org/location/latin_america/br azil/belo_horizonte> Acesso em 14 mar 2020.

CARVALHO, C. H. R. Emissões relativas de poluentes do transporte urbano.

Boletim regional, urbano e ambiental, n. 05, p. 123-139, 2011. Disponível em: $<$ http://repositorio.ipea.gov.br/bitstream/110 58/5574/1/BRU_n05_emiss\%c3\%b5es.pdf> Acesso em 06 jul 2020.
DUTRA, Cristiane Biazzono; BECKER, Alexandre Morande. A experiência das faixas exclusivas para ônibus na cidade de Londrina-Paraná. In: Congresso Brasileiro de Transporte e Trânsito. 2015. Disponível em: http://files-server.antp.org.br/_ 5dotSystem/download/dcmDocument/ 2015/06/12/5618120B-56DA-4319-8C48860219C8D849.pdf> Acesso em 20 mar 2020.

\section{ESPÍRITO SANTO. Tribunal de Justiça do estado do Espírito Santo ( ${ }^{a}$ Vara da Fazenda Pública Estadual, Municipal, \\ Registros Públicos, Meio Ambiente e Saúde). Ação Popular $\mathrm{n}^{\circ} 0007550$ - 48.2018.8.08.0024. Requerente(s): Licia Rezende Narciso. Requerido(s): Município de Vitória, Luciano Rezende, Tyago Hoffmann. Relator(a): Juiz Mario da Silva Nunes Neto, Vitória, julgamento e publicação da sentença em 21/03/2018. 2018a. Disponível em: \\ <http://aplicativos.tjes.jus.br/sistemaspublico s/consulta_12_instancias/ver_decisao_new.cf m> Acesso em 07 jul 2020.}

ESPÍRITO SANTO. Tribunal de Justiça do estado do Espírito Santo ( $3^{\text {a }}$ Vara da Fazenda Pública Estadual, Municipal, Registros Públicos, Meio Ambiente e Saúde). Ação Popular $n^{\circ}$ 0007550-48.2018.8.08.0024. Requerente(s): Licia Rezende Narciso. Requerido(s): Município de Vitória, Luciano Rezende, Tyago Hoffmann. Relator(a): Des. Raimundo Siqueira Ribeiro, Vitória, julgamento em 28/03/2018, publicação da decisão em 30/03/2018. 2018b. Disponível em: <http://aplicativos.tjes.jus.br/sistemas publicos/consulta_12_instancias/ver_sentenc a_new.cfm> Acesso em 07 jul 2020.

FERREIRA, Mariane Sobral Afonso et al. Uma análise da emissão de poluentes dos modais de transporte urbano brasileiro à luz do metabolismo social. 2019. Disponível em <http://www.repositorio.ufal.br/bitstream /riufal/6620/1/Uma\%20an\%c3\%a1lise\%20da $\% 20$ emiss $\%$ c3\%a3o\%20de\%20poluentes $\% 2$ 
0dos\%20modais\%20de $\% 20$ transporte $\% 20$ ur bano\%20brasileiro\%20\%c3\%a0\%20luz $\% 20$ do $\% 20$ metabolismo\%20social.pdf $>$ Acesso em 08 jul 2020

GODOY, Arilda Schmidt. Pesquisa qualitativa: tipos fundamentais. Revista de Administração de empresas, v. 35, n. 3, p. 20-29, 1995. Disponível em: $<$ https://www.scielo.br/pdf/rae/ v35n3/a04v35n3.pdf > Acesso em 07 jul 2020.

GOMES, Rafael. Multa de R $\$ 130$ a partir desta segunda na Linha Verde. Tribuna Online. Vitória, 24 de novembro de 2019. Disponível em:

$<$ https://tribunaonline.com.br/multa-de-r130-a-partir-desta-segunda-na-linha-verde> Acesso em 20 mar 2020.

IBGE (Instituto Brasileiro de Geografia e Estatística). IBGE, Cidades@: Vitória. 2020. Disponível em: <https://cidades.ibge.gov.br/brasil/es/vitoria/ panorama> Acesso em 14 mar 2020.

IEMA (Instituto de Energia e Meio Ambiente). Estudo sobre faixas exclusivasSão Paulo/SP. 2017. Disponível em: $<$ https://iema-sitestaging.s3.amazonaws.com/re_faixas_exclusi vas_final.pdf> Acesso em 14 mar 2020.

IPEA (Instituto de Pesquisa Econômica Avançada). Agenda 2030 - ODS - Metas Nacionais dos Objetivos de Desenvolvimento Sustentável. 2018. Disponível em: <https://www.ipea.gov.br/portal/images/stori es/PDFs/livros/livros/180801_ods_metas_na c_dos_obj

_de_desenv_susten_propos_de_adequa.pdf> Acesso em 28 out 2019.

KRIPKA, Rosana; SCHELLER, Morgana; BONOTTO, Danusa Lara. Pesquisa documental: considerações sobre conceitos e características na pesquisa qualitativa. CIAIQ2015, v. 2, 2015. Disponível em: $<$ https://proceedings.ciaiq.org/index.php/ciai q2015/article/view/252/248> Acesso em 07 jul 2020.

LINDAU, Luis Antonio et al. BRT e Corredores Prioritários para Ônibus: panorama no continente americano. 2013. In: XXVII ANPET-Congresso de Pesquisa e Ensino em Transportes. Disponível em: <https://www.thecityfixbrasil.org/wpcontent/uploads/2015/01/BRT-ECORREDORES-PRIORITARIOS-PARAONIBUS-PANORAMA-NOCONTINENTE-AMERICANO.pdf > Acesso em 20 mar 2020

MOTA, Caio Lima Souza Canabrava et al. Análise dos impactos causados pela implantação de faixas exclusivas de ônibus em grandes centros urbanos. Revista Mackenzie De Engenharia E Computação, v. 19, n. 1, 2019. Disponível em: <http://editorarevistas.mackenzie.br/ index.php/rmec/article/view/11001/7751> Acesso em 14 mar 2020.

NEVES, José Luis. Pesquisa qualitativa: características, usos e possibilidades. Caderno de pesquisas em administração, São Paulo, v. 1, n. 3, p. 1-5, 1996.

NTU (Associação Nacional das Empresas de Transportes Urbanos). Anuário NTU: 20182019. Brasília: NTU, 2019. Disponível em: <https://www.ntu.org.br/novo/upload/Publica cao/ Pub637020043450950070.pdf > Acesso em 28 out 2019.

\section{Os grandes números da}

mobilidade urbana - cenário nacional.

Brasília: NTU, 2020. Disponível em: $<$ https://www.ntu.org.br/novo/AreasInternas. aspx?idArea=7> Acesso em 22 abr 2020.

\section{Faixas Exclusivas de Ônibus}

Urbanos - Experiências de Sucesso. Brasília: NTU, 2013. Disponível em: <https://www.ntu.org.br/novo/upload/Publica cao/Pub635399779599334232.pdf> Acesso em 10 out 2019. 
OBSERVATÓRIO DO CLIMA. Análises das emissões brasileiras de gases de efeito estufa e suas implicações para as metas do Brasil (1970 - 2018). SEEG Brasil: Sistema de Estimativas de Emissões e Remoções de Gases de Efeito Estufa, 2019. Disponível em: <http://www.observatoriodoclima.eco.br/wpcontent/uploads/2019/11/OC_SEEG_Relatori o_2019p df.pdf> Acesso em 01 jul 2020.

OLIVEIRA, Rafael Martins de; MACHADO, Eduardo Luiz; PRINCE, Diogo de. Impactos da adoção de faixas exclusivas de ônibus: uma análise do caso de São Paulo. 2018. Disponível em: <https://www.unifesp.br/campus/osa2/image s/PDF/Dissertacao_Rafael_Martins_deOliveira_versa o_final_corrigida.pdf> Acesso em 14 mar 2020.

PARADEDA, Diego Benites et al. Implantaçao de faixas exclusivas para ônibus: efeito da troca modal no tráfego. 2015. Disponível em: <https://repositorio. ufsc.br/xmlui/handle/ 123456789/135990> Acesso em 14 mar 2020.

PONTES, Clarissa et al. Sobre o impacto da implantação de um corredor exclusivo para ônibus em centros urbanos: um estudo de caso para Belo Horizonte. 2014. Disponível em:

$<$ https://www.imtraff.com.br/wpcontent/uploads/2019/03/panam2014_submis sion_116.pdf $>$ Acesso em 20 mar 2020

PREFEITURA MUNICIPAL DE VITÓRIA (PMV). Prefeitura aposta na conscientização de motoristas na Linha Verde. PMV Imprensa. 10 de maio de 2018. Disponível em:

$<$ https://www.vitoria.es.gov.br/noticia/prefeit ura-aposta-na-conscientizacao-de-motoristasna-linha-verde-28444> Acesso em 20 mar 2020.

Relatório Técnico - Linha Verde.

Secretaria Municipal de Transportes, Trânsito e Infraestrutura Urbana (SETRAN). 22 de março de 2018.
Parecer Técnico No 017/2018 -

Secretaria Municipal de Transportes, Trânsito e Infraestrutura Urbana (SETRAN). Disponível em: <http://camarasempapel. cmv.es.gov.br/Arquivo/Documents/RRI/RRI 1332018.pdf> Acesso em 14 mar 2020.

Estudo do Plano Diretor de Transporte e Mobilidade Urbana de Vitória - Faixa Exclusiva de Ônibus. 2018. Disponível em: <http://camarasempapel. cmv.es.gov.br/Arquivo/Documents/RRI/RRI 1332018.pdf> Acesso em 14 mar 2020.

Resumo do Relatório da Primeira Fase da Implantação da Linha Verde na Dante Michelini. 2018.

SANTOS, Artur Bastos. Mobilidade pendular para trabalho no município de Vitória: relações com a migração intrametropolitana. 2018. Disponível em: <http://www.eng2018.agb.org.br/resources/a nais/8/1533686170_ARQUIVO_Mobilidade pendularparatrabalhonomunicipiodeVitoria_r elacoescomamigracaointrametropolitana.pdf > Acesso em 17 mar 2020.

SILVA, Eduardo Fernandez. Meio Ambiente \& Mobilidade Urbana. São Paulo: Ed. Senac (Série Meio Ambiente, 22 / Coordenação José de Ávila Aguiar Coimbra), 2019.

TATTO, Jilmar Augustinho. Mobilidade urbana em São Paulo: aplicação de soluções imediatas e eficazes. 2015. Tese de Doutorado. Universidade de São Paulo. Disponível em: <https://teses.usp.br/teses/disponiveis/3/3143 /tde-23092015-

131419/publico/Diss_JATatto.pdf> Acesso em 20 mar 2020

TRIGUEIRO, André. Prefácio in ANDRADE, V.; RODRIGUES, J.; MARINO, F.; LOBO, Z. (Org.). Mobilidade por bicicleta no Brasil. Rio de Janeiro: PROURB/UFRJ, 2016. Disponível em: 
<http://ta.org.br/educativos/docs/mbb.pdf> Acesso em 28 out 2019.

VASCONCELLOS, Eduardo A.; MENDONÇA, Adolfo. Política Nacional de Transporte Público no Brasil: organização e implantação de corredores de ônibus.

Revista dos Transportes Públicos - ANTP, p. 33 - 2010. 2010. Disponível em <http://files-server.antp.org.br/ 5dotSystem/download/ dcmDocument /2013/01/10/FEAB2631-4FA4-4C02-BA3D9D96919BB616.pdf> Acesso em28 out 2019.

VERLI, Caique. Linha Verde completa 1 ano em Vitória e ampliação não tem prazo. CBN Vitória. Vitória, 21 de março de 2019.

Disponível em:

<https://www.cbnvitoria.com.br/cbn_vitoria/ reportagens/2019/03/linha-verde-completa-1ano-em-vitoria-e-ampliacao-nao-tem-prazo1014173201.html> Acesso em 20 mar 2020.

VITÓRIA (Município). Lei n ${ }^{\circ}$ 9271, de 21 de maio de 2018. Plano Diretor Urbano do Município de Vitória. 2018. Vitória, ES, Disponível em:

$<$ http://camarasempapel.cmv.es.gov.br/Arqui vo/

Documents/legislacao/html/L92712018.html >. Acesso em 24 mar 2020. 